\title{
Why Providers Participate in Clinical Trials: Considering the National Cancer Institute's Community Clinical Oncology Program
}

\author{
Ann Scheck McAlearney, Sc.D., M.S. ${ }^{a, b}$, Paula H. Song, Ph.D. ${ }^{b}$, and Kristin L. Reiter, Ph.D.c \\ aDepartment of Family Medicine, College of Medicine, The Ohio State University, Columbus, $\mathrm{OH}$, \\ USA \\ ${ }^{b}$ Division of Health Services Management and Policy, College of Public Health, The Ohio State \\ University, Columbus, $\mathrm{OH}$, USA \\ 'Department of Health Policy and Management, The University of North Carolina at Chapel Hill, \\ Chapel Hill, NC, USA
}

\begin{abstract}
Background-The translation of research evidence into practice is facilitated by clinical trials such as those sponsored by the National Cancer Institute's Community Clinical Oncology Program (CCOP) that help disseminate cancer care innovations to community-based physicians and provider organizations. However, CCOP participation involves unsubsidized costs and organizational challenges that raise concerns about sustained provider participation in clinical trials.
\end{abstract}

Objectives-This study was designed to improve our understanding of why providers participate in the CCOP in order to inform the decision-making process of administrators, clinicians, organizations, and policy-makers considering CCOP participation.

Research Methods-We conducted a multi-site qualitative study of five provider organizations engaged with the CCOP. We interviewed 41 administrative and clinician key informants, asking about what motivated CCOP participation, and what benefits they associated with involvement. We deductively and inductively analyzed verbatim interview transcripts, and explored themes that emerged.

\footnotetext{
(C) 2012 Elsevier Inc. All rights reserved.

Contact Information for Correspondence and Reprint Requests: Professor Ann Scheck McAlearney, Department of Family Medicine, College of Medicine, The Ohio State University, 273 Northwood and High Building, 2231 North High Street, Columbus, OH 43201, Phone: (614) 292-0662; Fax: (614) 292-3572, mcalearney.1@osu.edu.

Ann Scheck McAlearney, Sc.D., M.S., Professor, Family Medicine, Department of Family Medicine, College of Medicine, The Ohio State University, 273 Northwood and High Building, 2231 North High Street, Columbus, OH 43201 USA, Phone: (614) 292-0662; Fax: (614) 292-3572, mcalearney.1@ osu.edu Paula H. Song, Ph.D., Assistant Professor, Health Services Management and Policy, College of Public Health, The Ohio State University, Cunz Hall 228, 1841 Neil Avenue, Columbus, OH 43210 USA, Phone: (614) 292-1428; Fax: (614) 292-3572, psong@cph.osu.edu

Kristin L. Reiter, PhD, Assistant Professor, Department of Health Policy and Management, The University of North Carolina at Chapel Hill, 1104H McGavran-Greenberg Hall, Chapel Hill, NC 27599-7411 USA, Phone: (919) 843-8619, reiter@email.unc.edu No conflict of interest exists with this manuscript.

Publisher's Disclaimer: This is a PDF file of an unedited manuscript that has been accepted for publication. As a service to our customers we are providing this early version of the manuscript. The manuscript will undergo copyediting, typesetting, and review of the resulting proof before it is published in its final citable form. Please note that during the production process errors may be discovered which could affect the content, and all legal disclaimers that apply to the journal pertain.
} 
Results-Interviewees expressed both "altruistic" and "self-interested" motives for CCOP participation. Altruistic reasons included a desire to increase access to clinical trials and feeling an obligation to patients. Self-interested reasons included the desire to enhance reputation, and a need to integrate disparate cancer care activities. Perceived benefits largely matched expressed motives for CCOP participation, and included internal and external benefits to the organization, and quality of care benefits for both patients and participating physicians.

Conclusion-The motives and benefits providers attributed to CCOP participation are consistent with translational research goals, offering evidence that participation can contribute value to providers by expanding access to innovative medical care for patients in need.

\section{Keywords}

clinical trials; cancer; community-based participatory research; health services research; qualitative research; organizational decision making; community networks; research support as topic

\section{INTRODUCTION}

With advances in clinical research rapidly changing the provision of medical care, the need to efficiently and effectively translate research evidence into practice is increasingly important [1-7]. Clinical trials serve a vital role in this evidence translation process as new treatments are offered to eligible patients by practicing providers willing to pursue clinical trials research and report their findings based on the experiences of their patients with the protocols under study.

In the area of cancer, the National Cancer Institute's (NCI) ${ }^{1}$ Community Clinical Oncology Program (CCOP), a provider-based research network (PBRN), helps to disseminate and implement innovations in cancer care by supporting a research infrastructure that links academic institutions and investigators to community-based physicians and medical groups $[5,8]$. The CCOP structure thus helps to promote advances in cancer treatments among community providers by expanding access to clinical trials and disseminating research findings about new interventions and technologies that might not be typically available [5,9$10]$.

Yet similar to the challenges of other clinical trials research, participation in the CCOP can involve costs to both hospitals and physicians that are not fully subsidized by the NCI [5]. Previous studies have identified several barriers to community physician participation in clinical trials research [5,11-15], and many challenges to sustaining such participation over the long term [5,15-17]. Less well understood is what motivates hospitals and community physicians to participate in clinical trials such as the CCOP, and what benefits they report from their participation.

We designed a qualitative study to learn more about the reasons organizations and physicians participate in the CCOP, including both what motivates their initial participation decisions, and their perceptions of the benefits they obtain that contribute to their decisions to continue to participate in the CCOP. We were especially interested in learning about these factors from the perspectives of the organizational and physician providers involved in the $\mathrm{CCOP}$, including those making decisions about CCOP participation. Improving our understanding of these motives and benefits can help inform the decision-making processes of administrators, clinicians, organizations, and policymakers considering the opportunities

\footnotetext{
${ }^{1}$ Abbreviations Used: National Cancer Institute (NCI); Community Clinical Oncology Program (CCOP); Provider-Based Research Network (PBRN)
} 
and potential impacts of CCOP participation in the context of challenging economic conditions.

\section{METHODS}

We used a multiple case-study design [18] in a qualitative study [19] to investigate the motives behind physician and organizational participation in the NCI's CCOP. Below we further describe our site selection, study sample, data collection, and analytic methods. The Institutional Review Boards of The Ohio State University and the University of North Carolina, Chapel Hill, approved the study protocol.

\section{Study Setting}

The NCI's CCOP was established in 1983 to extend the reach of Phase III clinical trials focused on cancer prevention, control and treatment to community practice settings. There are presently 47 CCOP organizations throughout the United States, representing 340 hospitals and 2,900 community-based physicians (e.g., oncologists, surgeons, OB/GYNs) [20]. We use the term "CCOP provider organizations" to refer to the hospitals and physician practices affiliated with the CCOP organizations.

Individual CCOP organizations receive peer-reviewed research grant funding through the $\mathrm{NCI}$, with grant awards dependent on research productivity and patient recruitment to clinical trials. However, CCOP grants are typically insufficient to cover the full costs associated with maintaining a research infrastructure [5], thus CCOP provider organizations commonly need to subsidize CCOP participation.

\section{Study Sample}

Given our study design, we purposively selected participating sites in order to ensure variability across CCOP organizations with respect to the dimensions of size, structure, location, and length of operations as a CCOP (i.e., CCOP maturity). Our study sample included five sites: two mature CCOP organizations, in operation for more than 10 years; two that had been part of the CCOP for fewer than 10 years; and one that had applied to the NCI's CCOP but had not yet been awarded a CCOP grant. At the conclusion of interviews across these fives sites we found that we had reached saturation with respect to respondents' answers to our questions, thus giving us confidence that our sample size was sufficient.

\section{Data Collection}

We conducted a total of 41 telephonic key informant interviews across the five study sites between August 2008 and April 2010. At each study site we identified a key contact person (e.g., the CCOP principal investigator or CCOP administrator). We then asked that person to identify additional key informants associated with the CCOP provider organization (both administrators and clinicians), and community-based practicing physicians who were involved in CCOP-related clinical trials research. Organizational key informants $(n=20)$ included those administrators and staff members who were involved in CCOP provider organization operations and included directors, managers, and finance personnel. Clinician key informants $(\mathrm{n}=18)$ included both physicians $(\mathrm{n}=11)$ and nurses $(\mathrm{n}=7)$, and included community-based physicians associated with all sites' CCOP provider organizations (see Table 1). Informed consent was obtained from all key informants.

Interviewers used two versions of a standardized guide (i.e., one for organizational informants and one for physician informants) to conduct the interviews. The interview guides were comprised of semi-structured questions and follow-up question probes, including direct questions about motives for and benefits of CCOP participation. The two 
interview guides asked similar questions of both respondent groups, but question wording was tailored to the professional role of the interviewee (i.e., physician versus nonphysician).

Questions about motives directed interviewees to consider the reasons why their organization or they had decided to participate in the CCOP (e.g., "What was your organization's primary motivation for becoming [part of] a CCOP organization?"). Questions about benefits asked interviewees to consider the benefits of CCOP participation, based on their experience with the CCOP (e.g., "How has your organization benefited from participation in the CCOP?"). Interviews lasted from 30-60 minutes. The majority of interviews were conducted by one study investigator, with a second investigator available on the call to assist. All interviews were recorded, transcribed verbatim, and then verified and corrected by study investigators.

\section{Analyses}

We used a combination of deductive and inductive methods to analyze our interview data. First, using a grounded theory approach [20-21], we read transcripts and discussed preliminary findings as our study progressed. Then, after completion of all the interviews, we formed an analysis team that included the lead qualitative investigator and two research assistants to code all the transcripts.

For the deductive portion of our study, we developed a preliminary coding book including codes based on responses to the direct questions that had been asked of key informants.

Coders then used this coding book to code the same three transcripts and come to agreement about codes and code definitions. As the study and coding processes progressed, coders met periodically in order to ensure consistency among coders and agreement about the emergence of themes within the data.

The inductive portion of our study involved iteratively analyzing interview transcripts to identify themes [22] related to motives and benefits of participation. Coders would identify these emergent themes, enabling us to then explore new themes in subsequent interviews as the case studies proceeded. We used the Atlas.ti qualitative data analysis software program to facilitate coding and analyses [23].

\section{RESULTS}

\section{Motives for Participation in the CCOP}

When asked why they participated in the CCOP, both organizational and physician interviewees provided two main types of reasons that we categorized thematically as "altruistic," or externally-focused reasons, and "self-interested," or internally-focused reasons. We next discuss these reasons by theme, and provide additional representative quotations in Table 2.

"Altruistic" Reasons for CCOP Participation-Interviewees listed multiple reasons for participating in the CCOP, many of which were related to concern about others outside their organization(s). These "altruistic" reasons included providing access to clinical trials for community residents and participating in research because it was what "should be done." For instance, interviewees across all five CCOP organizations noted CCOP participation was an important way to provide access to clinical trials for their patients or potential patients. Informants appeared convinced that offering clinical trials as treatment options was part of providing the best care possible, thus making trials available was viewed as clinically important. As one administrator explained, "I think the primary focus was to provide clinical 
trials here in [location] for our local cancer patients and not to make our patients travel so far for the trials." Another interviewee, summarizing what he/she believed to be the collective sentiment of that organization's participating physicians explained, "I really believe, from an altruistic standpoint, that the oncologists truly believe in the benefit of research and having that as an option available to patients."

As many interviewees' further explained, they felt a type of professional or even "moral" obligation to participate based on organizational or clinical goals. As described by one administrator, "I think it was jointly held values and the principle that as a leader in healthcare in the state, it was our obligation to work with physicians to bring state-of-the-art treatment to local populations across the state as much as possible." A physician similarly reflected how, "We looked at it and we said, this is an absolute. We can't take care of cancer patients without having access to clinical trials."

"Self-Interested" Reasons for CCOP Participation-Both organizational and physician interviewees also listed reasons for CCOP participation that were related to their organization's or their own interests. For example, the opportunity for CCOP participation to improve both the organizations' and the physicians' reputations was noted as an important motivator across interviewees. One administrator explained that CCOP participation was sought, "to advance the reputation of the institution." A physician summarized this motivator nicely for both groups explaining, "The reason we do this is that you want to make a name for yourself as an institution that can do this on its own."

Another type of internally-focused reason involved the desire to integrate and organize cancer services. As one administrator explained, "The main reason why we wanted to become a CCOP was to try and create a mechanism to really have one research program and one primary source of access to NCI-funded clinical trials." Similarly, a physician described, "We had a lot of duplication with some of our programs and we had pockets where we were doing some stuff, but we weren't doing others. So it really became part of helping us standardize and put together a complete picture around cancer." For the larger CCOP organizations, the motivation to integrate cancer activities was particularly strong.

\section{Perceived Benefits of CCOP Participation}

When asked about the benefits that CCOP participation provided, interviewees described multiple types of benefits. We categorized these benefits thematically into three groups: 1) internal organizational benefits; 2) external organizational benefits; and 3) quality of care benefits. Below we describe these themes in greater detail, with additional verbatim comments supporting these categorizations presented in Table 3.

Internal Benefits to Provider Organizations-Internal benefits to the provider organizations largely involved the issues of physician and patient recruitment and retention. For instance, interviewees across the five sites consistently noted that an important benefit of CCOP participation was an enhanced ability to recruit and retain physicians. As one administrator described a recent physician recruitment effort: "One of the specific questions that they [the physician candidates] had for us was what research we do here." Physicians similarly noted this benefit. One reflected, "We also have hired breast surgeons and so forth who've mentioned that part of their decision was that we have the clinical research available. That was an unanticipated but significant benefit of participating in the CCOP grant."

The ability to attract and retain patients was also commonly mentioned as a benefit of CCOP participation. As one administrator explained, "[W]hen our patients go [elsewhere], [the other hospital] will also send them back if we have a trial open here... So I'm certain that 
we're keeping more patients here because of our research participation." Both organizational and physician interviewees additionally noted that CCOP participation could involve spillover benefits to other areas of the hospital; as one organizational interviewee commented, "[It] helps them to increase the amount of patients who are having services here at the hospital."

External Organizational Benefits-Interviewees' descriptions of external benefits to the provider organizations largely involved the perception that CCOP participation enhanced their reputation in the community, thereby improving their organization's "status" and providing them with leverage for clinical trials. A majority of informants reported that they perceived that an improved reputation in their communities was indeed a benefit of CCOP participation, and this was consistent with their previous explanations that the potential for a better community reputation motivated CCOP participation. As one administrator noted, "A very good reputation, that comes along with it. Kind of like a status thing [from the perspective of] other institutions." Physicians were also quick to list this benefit, making comments about how they are now "on the map for cancer care," and that, "it makes the practice more prestigious."

This enhanced reputation through CCOP participation also reportedly benefited providers by giving both organizations and individual physicians leverage to expand their research activities, including involvement in pharmaceutical industry-sponsored clinical trials. This was reportedly a benefit because industry-sponsored trials were typically well-reimbursed, thus additional trial participation could contribute to efforts to support and sustain the cancer research infrastructures of these provider organizations. One administrator explained, "being a CCOP, we have to already have established certain certifications and things like that so that's going to make us more appealing and desirable. Because we've already done a lot of the groundwork and footwork and have processes in place."

Quality of Care Benefits-In addition, quality of care benefits were consistently noted across sites and interviewees. These benefits included interviewees' perceptions that CCOP participation benefited physicians by providing opportunities for continuing education, and the notion that this continuing education thereby enabled provision of higher-quality care. Specifically, helping physicians stay current with advances in cancer therapies was mentioned by both interviewee groups as an important benefit of CCOP participation. As one administrator mentioned, "So I think it's just a good way to get everybody well educated in terms of what is going on in the rest of the country in terms of clinical trials. I think it's also a good way for them to stay in tune with the literature. Follow it." The specific opportunity the CCOP provided for physicians to network with other physicians to keep abreast of developments in cancer treatments was also mentioned in this context. One physician commented, "You know, it's a chance to network. When you go to these meetings [CCOP meetings] and you talk to other physicians from other institutions, you also bring back something you don't practice. I think it's a chance to be more involved with cuttingedge care and bring it back to your institution."

In addition, interviewees' reportedly believed that CCOP participation involved the opportunity to provide better care quality explicitly because of access to clinical research trials through the CCOP. As one administrator noted, "I just think that there is more awareness as to what's state-of-the-art and potentially what will be state-of-the-art in a year or two." Physicians were similarly positive about their abilities to offer better care to patients. One physician explained, "It drives the quality of the oncology group, then drives the quality of the other specialists because they demand the same kind of attention to detail and attention to conferences and review of patients and transparent care patterns, high use of 
the protocol, etc. So it creates an academic environment that helps us sustain the whole thing."

\section{DISCUSSION}

This study was designed to improve our understanding of why providers were motivated to participate in a CCOP, and to learn about the benefits they perceived to be associated with that participation in order to help the broad audience of administrators, organizations, clinicians and policymakers who may be considering the opportunities and potential impacts of CCOP participation. We found that the interviewees we spoke with about their CCOP involvement shared similar perspectives about the motives and benefits of CCOP participation, with the motives often linked to their perceptions about the benefits of participation. For example, many interviewees noted that they participated in the CCOP because they hoped to improve their reputations as either organizations or providers, and they later noted that improved reputations were benefits they associated with CCOP participation.

Overall, organizational and physician interviewees reported both "altruistic" (external) and "self-interested" (internal) motives for CCOP participation. These motives are consistent with the results of prior studies showing that CCOPs have a positive global impact on research, despite findings that certain types of cancer research may only indirectly impact the participating organization, its patients and its providers [24]. Similarly, our findings about the perceived benefits of participation are aligned with the results of recent research that have shown that CCOP participation is associated with increases in accruals to clinical trials [e.g., 25-26], thus providing evidence that CCOP participation can help provider organizations expand and support their cancer research efforts.

Yet given the current economic climate and financial pressures placed upon provider organizations, the sustainability of CCOP organizations as important players in clinical trials research networks is not guaranteed [4-5,12-15]. Our study suggests that there are numerous organizational and societal benefits of CCOP participation (e.g., better quality of care), and these were noted across informant groups. Further, our interviewees' reflections about participation benefits are consistent with the goals of the NCI's CCOP, and research that has demonstrated the value of CCOPs as a means of effectively translating research into practice [25-28]. The next step, though, must involve additional effort to measure a business case for CCOP participation, particularly in the face of an increasing need for organizations to justify continued financial support of activities such as CCOP studies that are an invaluable component of translational and dissemination research, but may not contribute obviously or directly to the organization's bottom line [29-33].

Interestingly, while interviewees' reported many intangible motives for CCOP participation (e.g., being the "right thing to do," improving their reputations), the benefits they reported associating with participation could conceivably be quantified. For instance, reported improvements in physician and patient recruitment and retention were not explicitly expected, but were noted across all sites, and could be measured if organizations wanted to track the impact of CCOP participation. Similarly, unexpected quality of care benefits could be monitored with respect to patient outcomes, physician compliance with guidelines and protocols, and so forth. More directly, provider organizations could track their progress with respect to obtaining research contracts and grants with pharmaceutical companies and other agencies, thereby providing tangible evidence of the benefits of CCOP participation.

From a policy and research perspective, the NCI can help sustain the CCOP by using the results of this study to explicitly strengthen motives for CCOP participation and enhance 
both participation benefits and awareness of these benefits. While the challenges of documenting these benefits and quantifying a business case remain, the results of our study highlight the importance of both tangible and non-financial benefits that can and should be taken into account in any assessment of the value of clinical trials, and particularly CCOP, participation.

\section{Limitations}

Predictably, our study has a number of limitations. First, while our site selection approach was comprehensive, our research design limited our study to five purposively selected CCOP organizations. It is possible that a different set of CCOP organizations might have allowed us to explore different motives and benefits of CCOP participation. In addition, our approach to key informant selection could have biased our findings in favor of CCOP participation, as all informants had knowledge of the CCOP and its activities. Nonetheless, our multiple interviews of both organizational and physician representatives across the five sites give us confidence that our findings do resonate with interviewees across these varied CCOP organizations, and that our findings are consistent across informant types.

Our study is also limited by the time frame during which it was conducted. Recognizing that NCI funding and CCOP participation are, in practice, dynamic processes, we were limited by our ability to interview informants at a single point in time. Finally, our findings may be limited in their applicability to cancer research and cancer clinical trials. It is conceivable that the motives and benefits we find associated with CCOP participation may be less compelling in other fields where state-of-the art clinical trials are less common.

Future studies can help extend this research by using designs that are both longitudinal and quantitative, and use opportunities to blend qualitative considerations with measures of quality of care and outcomes associated with trial participation.

\section{Conclusion}

Given the importance of disseminating and implementing innovations in medical care, our research shows that the motives providers report for participating in CCOPs are consistent with translational research goals. Further, our findings support the value of CCOPs in helping both organizations and physicians in their efforts to expand access to clinical trials research to local communities and patients for whom such access might not otherwise be available. A better understanding of these motives and benefits can help both provider organizations and physician providers justify and sustain their commitment to clinical trials and the CCOP over time, thus maintaining critical access to innovative care for patients in need.

\section{Acknowledgments}

The authors greatly appreciate the time of all the informants and organizations who participated in this study. We also thank our research team members, Erin Schaffer, Padmini Ekbote, Alexandra Moss, and J. Phil Harrop for their assistance in early work on this study. We are especially grateful to Dr. Bryan Weiner and Dr. Lori Minasian for their support of this research and thoughtful suggestions that helped us to improve this manuscript. The project described was supported by Award Number R01CA124402 from the National Cancer Institute. The content is solely the responsibility of the authors and does not necessarily represent the official views of the National Cancer Institute or the National Institutes of Health.

\section{References}

1. Zerhouni E. Translational and clinical science - time for a new vision. N Engl J Med. 2005; 353:1621-3. [PubMed: 16221788] 
2. Zerhouni E. US biomedical research: basic, translational, and clinical sciences. J Am Med Assoc. 2005; 294:1352-58.

3. Lenfant C. Shattuck lecture--clinical research to clinical practice--lost in translation? N Engl J Med. 2003; 349:868-74. [PubMed: 12944573]

4. Lamb, S.; Greenlick, MR.; McCarty, D. Bridging the Gap Between Practice and Research. Washington, DC: National Academy Press; 1998.

5. Minasian LM, Carpenter WR, Weiner BJ, et al. Translating research into evidence-based practice: The National Cancer Institute Community Clinical Oncology Program. Cancer. 2010; 116:4440-49. [PubMed: 20572032]

6. National Cancer Institute. The NCI Strategic Plan for Leading the Nation To Eliminate the Suffering and Death Due to Cancer. National Cancer Institute; Rockville, MD: 2007.

7. National Institutes of Health (NIH). [Accessed May 17, 2011.] NIH Roadmap for Medical Research. Available at: http://nihroadmap.nih.gov/

8. National Cancer Institute. [Accessed May 3, 2011.] About the Community Clinical Oncology Program: History and Accomplishments. 2011. Available at: http://dcp.cancer.gov/programsresources/programs/ccop/about/history

9. Kiefe CI, Sales A. A state-of-the-art conference on implementing evidence in health care. Reasons and recommendations. J Gen Intern Med. 2006; 21(suppl 2):S67-S70. [PubMed: 16637964]

10. Sales A, et al. Models, strategies, and tools. Theory in implementing evidence-based findings into health care practice. J Gen Intern Med. 2006; 21 (Suppl 2):S43-9. [PubMed: 16637960]

11. McKinney M, Weiner BJ, Carpenter WR. Building community capacity to participate in cancer prevention research. Cancer Control. 2006; 13:295-302. [PubMed: 17075567]

12. Ryan G, Berrebi C, Beckett M, et al. Reengineering the clinical research enterprise to involve more community clinicians. Implement Sci. 2011; 6(36):1-7. [PubMed: 21208425]

13. Kahn K, Ryan G, Beckett M, et al. Bridging the gap between basic science and clinical practice: a role for community clinicians. Implement Sci. 2011; 6(1):1-11. [PubMed: 21208425]

14. Beckett M, Quiter E, Ryan G, et al. Bridging the gap between basic science and clinical practice: The role of organizations in addressing clinician barriers. Implement Sci. 2011; 6(35):1-10. [PubMed: 21208425]

15. Weiner BJ, McKinney M, Carpenter WR. Adapting clinical trials networks to promote cancer prevention and control research. Cancer. 2006; 106:180-7. [PubMed: 16333855]

16. Carpenter WR, Weiner BJ, Kaluzny AD, et al. The effects of managed care and competition on community based clinical research. Med Care. 2006; 44:671-679. [PubMed: 16799362]

17. Sung NS, Crowley WFJ, Genel M, et al. Central challenges facing the national clinical research enterprise. J Am Med Assoc. 2003; 289:1278-87.

18. Yin, DRK. Case Study Research: Design and Methods (Applied Social Research Methods). Sage Publications, Inc; 2008.

19. Maxwell, JA. Qualitative Research Design: An Interactive Approach. Sage Publications, Inc; 2004.

20. National Cancer Institute. NIH Publication No. 11-7721. Jan. 2011 Community Clinical Oncology Program \& Minority Based-Community Clinical Oncology Program: Accomplishments in Cancer Research.

21. Strauss, A.; Corbin, J. Basics of qualitative research: techniques and procedures for developing grounded theory. Thousand Oaks, CA: Sage; 1998.

22. Glaser BG, Strauss A. The Discovery of Grounded Theory: Strategies for Qualitative Research. Aldine Transaction. 1967

23. Miles, MB.; Huberman, AM. Qualitative data analysis: An expanded sourcebook. Sage Publications, Inc; 1994.

24. Atlas.ti [computer program]. Version 6.0. Berlin: Scientific Software Development; 2009.

25. Loprinzi CL, Barton DL, Jatoi A, et al. J Support Oncol. Symptom control trials: a 20-year experience. J Support Oncol. 2007; 5:119-25. 128. [PubMed: 17410810]

26. Witt RL, Frelick RW. Head and neck cancer care at a community-based teaching hospital. Head Neck. 2005; 27:613-5. [PubMed: 15825202] 
27. Klabunde C, Kaluzny A, Ford L. Community Clinical Oncology Program participation in the Breast Cancer Prevention Trial: factors affecting accrual. Cancer Epidemiol Biomarkers Prev. 1995; 4:783-9. [PubMed: 8672997]

28. Carpenter WR, Reeder-Hayes K, Bainbridge J, et al. The Role of Organizational Affiliations and Research Networks Channels in the Diffusion of Breast Cancer Treatment Innovation. Med Care. 2011; 49:172-9. [PubMed: 21206296]

29. McFall SL, Warnecke RB, Kaluzny AD, Ford L. Practice setting and physician influences on judgments of colon cancer treatment by community physicians. Health Serv Res. 1996; 31:5-19. [PubMed: 8617610]

30. Reiter KL, Kilpatrick KE, Greene SB, Lohr KN, Leatherman S. How to develop a business case for quality. Int J Qual Health Care. 2007; 19:50-55. [PubMed: 17172600]

31. Leatherman SD, Berwick D, Iles LS, et al. The business case for quality: case studies and an analysis. Health Aff. 2003; 22:17-30.

32. Reiter KL, Song PH, Good M, Minasian L, Weiner BJ, McAlearney AS. A method for measuring the business case for provider participation in the National Cancer Institute's Community Clinical Oncology Program and other similarly funded Provider-Based Research Networks. Cancer. Article first published online: 27 DEC 2011. 10.1002/cncr.27375.

33. Song P, Robbins J, Garman A, McAlearney AS. High-Performance Work Systems in Healthcare Management, Part 3: The role of the business case for HPWP investment in health care. Health Care Manage Rev. 2012; 37:110-121. [PubMed: 21918465] 
Table 1

CCOP Case Study Site Characteristics

\begin{tabular}{|c|c|c|c|c|}
\hline CCOP Site & $\begin{array}{l}\text { CCOP Maturity (Years in } \\
\text { Operation as CCOP) }\end{array}$ & CCOP Market Area & $\begin{array}{c}\text { Annual Patient } \\
\text { Accruals to NCI/ } \\
\text { DCP Clinical Trials }\end{array}$ & $\begin{array}{l}\text { Key Informants Interviewed } \\
(n=41)\end{array}$ \\
\hline 1 & $\begin{array}{l}\text { Applied recently for CCOP } \\
\text { grant }\end{array}$ & $\begin{array}{ll}\text { - } & \text { Highly competitive } \\
\text { - } & \text { Urban }\end{array}$ & $\sim 300-500$ & $\begin{array}{l}\text { Administrators }(\mathrm{n}=7) \\
\text { Physicians }(\mathrm{n}=5) \\
\text { Nurses }(\mathrm{n}=1)\end{array}$ \\
\hline 2 & $5-10$ years & $\begin{array}{ll}\text { - } & \text { Competitive } \\
\text { - } & \text { Urban }\end{array}$ & $\sim 500-800$ & $\begin{array}{l}\text { Administrators }(n=4) \\
\text { Physicians }(n=3) \\
\text { Nurses }(n=2)\end{array}$ \\
\hline 3 & $5-10$ years & $\begin{array}{l}\text { - } \quad \text { Competitive } \\
\text { - Urban }\end{array}$ & $\sim 250-300$ & $\begin{array}{l}\text { Administrators }(\mathrm{n}=2) \\
\text { Physicians }(\mathrm{n}=1) \\
\text { Nurses }(\mathrm{n}=0)\end{array}$ \\
\hline 4 & Over 10 years & $\begin{array}{ll}\text { - } & \text { Competitive } \\
\text { - } & \text { Urban }\end{array}$ & $\sim 1000$ & $\begin{array}{l}\text { Administrators }(\mathrm{n}=6) \\
\text { Physicians }(\mathrm{n}=2) \\
\text { Nurses }(\mathrm{n}=3)\end{array}$ \\
\hline 5 & Over 10 years & $\begin{array}{ll}\text { - } & \text { Less competitive } \\
\text { - } & \text { Rural }\end{array}$ & $\sim 500$ & $\begin{array}{l}\text { Administrators }(n=3) \\
\text { Physicians }(n=2) \\
\text { Nurses }(n=0)\end{array}$ \\
\hline
\end{tabular}


Table 2

\section{Motives for CCOP Participation}

\begin{tabular}{|c|c|c|}
\hline & Organizational Perspectives & Physician Perspectives \\
\hline “Altruistic,” Externally-Focused Motives & $\begin{array}{l}\text { "... primary motivation was to present clinical trials } \\
\text { for patients so that it's nearer to their home versus } \\
\text { going, you know, outside of their area to obtain } \\
\text { clinical trials." } \\
\text { "We have the only central city medical center in } \\
\text { [location]. So part of it I think was a responsibility to } \\
\text { go after this." } \\
\text { "I think that we're a non-profit community hospital } \\
\text { and we're here to serve the community in which we } \\
\text { reside so all of our decisions are based on how to } \\
\text { best serve our community." } \\
\text { "So our primary motivation was that as a healthcare } \\
\text { system, clinical research was a high priority across } \\
\text { the United States. It should be a high priority for the } \\
\text { quality of care that we wanted to provide." } \\
\text { "[W]e definitely believe that participating in clinical } \\
\text { trials is the right way to go in terms of pushing the } \\
\text { organization forward"" }\end{array}$ & $\begin{array}{l}\text { "the CCOP basically allows us to put } \\
\text { clinical trials into the community where } \\
\text { the majority of patients are being } \\
\text { treated." } \\
\text { "getting these studies to the rural areas } \\
\text { that would not typically be able to have } \\
\text { them without the CCOP being here." } \\
\text { "So our involvement was purely } \\
\text { academic and helping human kind... I } \\
\text { mean we never thought of ... oncology } \\
\text { as a business. So we had very pure } \\
\text { motives." } \\
\text { "Probably the main motivation ... } \\
\text { everything we do is a patient-centered } \\
\text { approach: our vision is centered on the } \\
\text { patient." } \\
\text { "When we started initially it was for } \\
\text { academia." }\end{array}$ \\
\hline $\begin{array}{r}\text { "Self-Interested," Internally- Focused } \\
\text { Motives }\end{array}$ & $\begin{array}{l}\text { "We wanted to see our own program as opposed to } \\
\text { being an affiliate." } \\
\text { "...enhance [the organization's] position and its } \\
\text { ability to offer services..." } \\
\text { "So I think the motivation of the greater } \\
\text { [organization] is to bring us all together, you know, } \\
\text { somewhat simplify the mechanism that's happening } \\
\text { in many areas throughout the oncology practice of } \\
\text { [location] and, again, have perhaps a little better } \\
\text { control over what's occurring." } \\
\text { "So if we had a CCOP then if you open up a study, it } \\
\text { opens up system-wide. That would have really cut } \\
\text { down on the amount of paperwork and the amount of } \\
\text { time it takes to open up one study at each site. And } \\
\text { that was actually one of the important things." }\end{array}$ & $\begin{array}{l}\text { "the CCOP was a way to distinguish us } \\
\text { as a major provider of oncology care in } \\
\text { this area." } \\
\text { "...it would be a prestigious thing to } \\
\text { have. It will be recognized as something } \\
\text { - a feather in your cap to be a CCOP." } \\
\text { "And you know when you have a lot of } \\
\text { private practice physicians, oncologists, } \\
\text { who then come together, it would be } \\
\text { nice to have that platform for them to } \\
\text { come together on. ...The CCOP would } \\
\text { have really allowed for us to } \\
\text { reorganize." }\end{array}$ \\
\hline
\end{tabular}


Table 3

\section{Perceived Benefits of CCOP Participation}

\begin{tabular}{|c|c|c|}
\hline & Organizational Perspectives & Physician Perspectives \\
\hline Internal Organizational Benefits & $\begin{array}{l}\text { "[I]t has helped us in the recruitment of } \\
\text { physicians... The new doctors coming out of } \\
\text { school want to go to a place that offers clinical } \\
\text { trials and that they can participate in research.". } \\
\text { "to bring in better physicians, to engage physicians } \\
\text { at a higher level" } \\
\text { "I know there are patients that know [this } \\
\text { organization] because of the CCOP." } \\
\text { "You know, we retain patients here. They kind of } \\
\text { walk them through every step of the way } \\
\text { throughout their care." }\end{array}$ & $\begin{array}{l}\text { "Attracting and retaining high-quality physicians. } \\
\text {..I think having the CCOP has made that easy." } \\
\text { "And the unexpected benefit as far as getting } \\
\text { better doctors will also get you more patients." } \\
\text { "So we benefit by having that additional business } \\
\text { that you know drives and feeds everybody's work } \\
\text { around here. So you come here with an oncology } \\
\text { problem and you end up having a neurologic } \\
\text { problem. ... so everybody benefits." }\end{array}$ \\
\hline External Organizational Benefits & $\begin{array}{l}\text { "And I think it also enhanced our reputation among } \\
\text { patients and residents of [this area] and around to } \\
\text { know that they can rely on us and they don't have } \\
\text { to go [to other places]." } \\
\text { "it elevates the community's impression of the } \\
\text { institution." "it has definitely helped us bring in } \\
\text { pharmaceutical contracts and things like that." } \\
\text { "I think it's also increased our reputation as being } \\
\text { an organization that is committed to research, that } \\
\text { is committed to being cutting-edge." } \\
\text { "I certainly think other funders would view that as } \\
\text { a positive if they were making a decision about } \\
\text { placing their funds within a particular organization } \\
\text { to know that an organization had achieved the } \\
\text { status of being a CCOP." }\end{array}$ & $\begin{array}{l}\text { "There is, you know, prestige, and the fact that } \\
\text { your practice is very well-respected and having } \\
\text { the ability to claim that you are a part of the } \\
\text { National Cancer Research Institute network has a } \\
\text { lot of value." } \\
\text { "I think that the CCOP would probably make us } \\
\text { more attractive because it sort of lends an air of } \\
\text { organization. ... otherwise you wouldn't have } \\
\text { been awarded the CCOP grant." } \\
\text { "we are large enough as a CCOP that now that } \\
\text { NCI, you know, they almost can't do some of the } \\
\text { big studies without engaging us." } \\
\text { "You know, if you develop a reputation as } \\
\text { somebody that is a guardian of the data and you } \\
\text { take that seriously, that reputation's going to carry } \\
\text { over to those trials. And I think pharmaceutical } \\
\text { companies are smart enough to know there are } \\
\text { certain places they're going to stay away from and } \\
\text { there are certain places they're going try to go to } \\
\text { to open trials up." }\end{array}$ \\
\hline Quality of Care Benefits & $\begin{array}{l}\text { "Whether it's new guidelines, new clinical } \\
\text { pathways, new options for treatment. Things like } \\
\text { that to keep it in the forefront and push things that } \\
\text { it's designed to push our outcomes to a higher } \\
\text { level." } \\
\text { "The quality of care is higher because of their } \\
\text { involvement within research." } \\
\text { "Those are things that are standard now, but they } \\
\text { were done earlier here because we were } \\
\text { participating in trials." } \\
\text { "It's allowed us to be able to offer to our patients a } \\
\text { much broader spectrum of treatment options." }\end{array}$ & $\begin{array}{l}\text { "I think when you are actively involved in } \\
\text { research protocols it really keeps you actively } \\
\text { involved in what is going on and changes and the } \\
\text { trends." } \\
\text { "So I guess that makes me feel current...and it } \\
\text { makes me feel that I'm contributing to an effort so } \\
\text { I won't have to tell the patients the same old tired } \\
\text { stuff that I've been telling them for the last } 25 \\
\text { years." } \\
\text { "And what it's helped me do is to give patients } \\
\text { cutting-edge treatments that wouldn't be available } \\
\text { otherwise." } \\
\text { "Getting new drugs to patients, changing the way } \\
\text { that we practice oncology. Those are the two } \\
\text { major benefits." }\end{array}$ \\
\hline
\end{tabular}

